NBER WORKING PAPER SERIES

\title{
THE ORGANIZATION OF INNOVATION: PROPERTY RIGHTS AND THE OUTSOURCING DECISION
}

\author{
Thomas Jungbauer \\ Sean Nicholson \\ June Pan \\ Michael Waldman \\ Working Paper 28379 \\ http://www.nber.org/papers/w28379 \\ NATIONAL BUREAU OF ECONOMIC RESEARCH \\ 1050 Massachusetts Avenue \\ Cambridge, MA 02138 \\ January 2021
}

We are grateful to Catherine Barrera, Kevin Bryan, Christopher Cairns, Yi Chen, Florian Ederer, Soheil Ghili, George Jakubson, Francine Lafontaine, Jorge Lemus, Sherif Nasser, Marcel Preuss, Mark Satterthwaite, Christian Schmid, and Rainer Widmann, Heidi Williams, unnamed seminar participants, as well as participants of the first virtual 2020 Annual Conference of the Society for Institutional and Organizational Economics (SIOE) for helpful comments, and thank Kiran Butte, Yujie Feng, and Qiwei He for valuable research assistance. An earlier draft of this paper was circulated under the title "The Organization of Innovation: Theory and Evidence from the Pharmaceutical Industry. The views expressed herein are those of the authors and do not necessarily reflect the views of the National Bureau of Economic Research.

NBER working papers are circulated for discussion and comment purposes. They have not been peer-reviewed or been subject to the review by the NBER Board of Directors that accompanies official NBER publications.

(C) 2021 by Thomas Jungbauer, Sean Nicholson, June Pan, and Michael Waldman. All rights reserved. Short sections of text, not to exceed two paragraphs, may be quoted without explicit permission provided that full credit, including $\odot$ notice, is given to the source. 
The Organization of Innovation: Property Rights and the Outsourcing Decision

Thomas Jungbauer, Sean Nicholson, June Pan, and Michael Waldman

NBER Working Paper No. 28379

January 2021

JEL No. D23,L24,L65,O32

\section{$\underline{\text { ABSTRACT }}$}

Why do firms outsource research and development (R\&D) for some products while conducting R\&D in-house for similar ones? An innovating firm risks cannibalizing its existing products. The more profitable these products, the more the firm wants to limit cannibalization. We apply this logic to the organization of R\&D by introducing a novel theoretical model in which developing in-house provides the firm more control over the new product's location in product space. An empirical analysis of our testable predictions using pharmaceutical data concerning patents, patent expiration, and outsourcing at various stages of the R\&D process supports our theoretical findings.

Thomas Jungbauer

Cornell University

Johnson Graduate School of Management

401A Sage Hall

114 East Ave

Ithaca, NY-14853

Ithaca, NY 14853

jungbauer@cornell.edu

Sean Nicholson

Department of Policy Analysis

and Management

Cornell University

102 Martha Van Rensselaer Hall

Ithaca, NY 14853

and NBER

sn243@cornell.edu
June Pan

VISA

Washington, DC

United States

junepan89@gmail.com

Michael Waldman

Johnson Graduate School of Management

323 Sage Hall

Cornell University

Ithaca, NY 14853-6201

mw46@cornell.edu

A online appendix is available at http://www.nber.org/data-appendix/w28379 


\section{Introduction}

A firm selling products for which its market power is substantial will want to deter the introduction of close substitutes that would cannibalize sales of these already profitable products. $^{1}$ One possibility is that this threat comes from a product introduced by a competitor. ${ }^{2}$ Another possibility, however, is that the threat comes from new products the firm itself introduces, in which case the firm will want to control the development process in order to limit cannibalization. We show how this basic argument explains the organization of innovation in high tech industries. In particular, using a property rights theory of the firm approach (Grossman and Hart, 1986; Hart and Moore, 1990; Hart, 2017), we show both theoretically and empirically that a firm will sometimes choose in-house development over outsourcing to limit cannibalization of patented products in its existing product portfolio.

Despite the popularity of outsourcing, partnering with an outside firm is not without costs. It is well known that one of the first and foremost dangers when outsourcing tasks crucial to the success of a company is loss of managerial control (Patel, 2017). Such a lack of control is more costly if misaligned incentives affect other successful business ventures of the outsourcing firm. ${ }^{3}$ This is particularly troublesome, as according to Lam (2004), "the needs that prompt companies to seek partners are generally ones that can't be fully specified. The product or capability may not even exist. A complete contract can't be written."

In the late 1990's and early 2000's the research-based biopharmaceutical company AstraZeneca, for example, initiated 20 new anti-cancer and 5 new biotechnology drug developments. While it outsourced the development of every single one of the biotechnology drugs, it developed all the anti-cancer drugs in-house. At the time, AstraZeneca did not hold a single patent in the class of biotechnological drugs, but had filed for 9 patents of anti-cancer drugs in the previous decade, including the well-known and successful compounds "Cosudex" and "Iressa" among others. ${ }^{4}$ In this paper, we argue that firms are in fact systematically more reluctant to relinquish control over the development, research and design of new products, the more successfully they already operate in the same product category.

We start by constructing and analyzing a theoretical model that formalizes our basic argument. In our model, a firm, called the originator, develops a new product and chooses

\footnotetext{
${ }^{1}$ This basic point can be traced back to a discussion in Arrow (1962).

${ }^{2}$ In a recent paper, Cunningham et al. (2020) investigate competition can lead to "killer acquisitions," i.e., firms with market power acquiring products in development and then discontinuing the R\&D efforts.

${ }^{3} \mathrm{Jim}$ Hall, president at the time of life science at advisory firm Wood Mackenzie recalls "a 60-70 million deal between a large pharmaceutical company and a medium-sized biotech firm falling apart when the biotech found that the more 'successful' the alliance became, the more money it would lose." Indeed, incompatible objectives rank among the top reasons for alliance failure in the business world (Lam, 2004).

${ }^{4}$ See the Pharmaprojects dataset.
} 
whether to conduct the remaining $R \& D$ in-house or outsource. The firm that conducts the R\&D cannot perfectly control the exact location of the new product in product space, but instead chooses a mean location and an investment level that determines the expected distance of the realized location from the mean location. A higher investment level translates into a smaller expected distance from the mean. We capture the cost of cannibalization by assuming that the originator also owns an existing patented product in the same product class as the new one. We consider a multiple periods model in which the cost of cannibalization is a function of the existing product's patent expiration date. For each possible period of patent expiration, the analysis compares the investment in location precision when the R\&D is conducted in-house with the investment when it is outsourced. We then build on this comparison to characterize equilibrium behavior.

Our analysis generates three testable predictions. First, compared to firms that do not own existing patented products, a firm that does is more likely to undertake R\&D in-house for a new product in the same product class as one of its existing patented products. Second, the probability of in-house development is positively related to the remaining patent duration of the existing patented product. Third, the probability of in-house development is positively related to the expected market share of the existing patented product at the date the new product is expected to reach the market. In each case, the basic logic behind these predictions follows the same path. The incentive to choose in-house development is higher the more profitable is the cannibalized product in the absence of the new product introduction.

We test these predictions using comprehensive data from the pharmaceutical industry, in which the patent system is a defining feature, and a large number of firms employ both in-house as well as outsourced development. Using detailed compound-level data from the Pharmaprojects dataset, we find strong empirical support for all three testable predictions. First, we find that the probability of in-house development increases when the originating firm has one or more existing patented compounds in the same therapeutic class as the compound under development. Second, given the presence of existing patented compounds in the same therapeutic class, the probability of in-house development increases with the remaining patent lengths of these compounds. Third, by supplementing the main data source with IMS sales data, ${ }^{5}$ we are able to show that the originator is more likely to develop the new compound in-house the higher is the market share the firm expects for its same-class patented drugs at the time the new compound is expected to reach the market.

The main message of this paper is that the vertical integration decision depends on factors not covered by the mainstream theories of vertical integration. Specifically, models of

\footnotetext{
${ }^{5}$ IMS Health is an American company that provides data and related services to the healthcare industry. IMS is now part of IQVIA.
} 
vertical integration typically focus either on the characteristics of an input and/or the final product(s). ${ }^{6}$ Our argument, however, is fundamentally different. In our model, whether or not to conduct R\&D in-house depends on the characteristics of products in the firm's product portfolio for which the R\&D is not an input. Even though the R\&D is not an input for these "other" products, the specific nature of the R\&D can affect the value of these other products resulting in a benefit of developing a new product in-house. Our empirical analysis of the pharmaceutical industry shows that this is an important driver of the in-house versus outsourcing decision in high-tech industries.

Another important aspect of our findings concerns the impact of competition on the vertical integration decision. Some of the papers that investigate the relationship between product market competition and vertical integration find a positive relationship, while others identify a negative one. We find that in the case of $R \& D$ the relationship is more nuanced. Specifically, we find that the likelihood of outsourcing increases with the level of competition. The driving force behind this result, however, is that competition negatively affects the profitability of an existing patented product. As a consequence, the incentive to avoid cannibalization of existing products by developing the new product in-house becomes less important, and outsourcing more attractive, the more competitive the market.

The outline for the paper is as follows. The next section reviews the relevant literature. Section 3 then presents the model and provides a preliminary analysis. Section 4 presents a full equilibrium analysis and discusses our testable predictions. Section 5 describes the data used in the empirical testing. Section 6 presents the empirical analysis. Section 7 discusses the extent to which our findings can be explained by alternative theories concerning the in-house versus outsourcing decision. Section 8 presents concluding remarks. The proofs of in text results are found in Appendix A. Appendix B generalizes our theoretical results introducing competition and multiple R\&D activities.

\section{Literature Review}

This paper contributes to the extensive literature on the property rights theory of the firm following the seminal papers of Grossman and Hart (1986) and Hart and Moore (1990). ${ }^{7}$ The property rights theory of the firm postulates that contracts are incomplete, and vertical

\footnotetext{
${ }^{6}$ One exception is Novak and Stern (2009) that finds empirical evidence in automobile production for complementarity concerning vertical integration decisions involving inputs closely related in the production process. They provide two possible explanations for the result, neither of which, however, is related to our argument. See also Barrera and Waldman (2019) for a related analysis.

${ }^{7}$ See Gibbons (2005) and Lafontaine and Slade (2007) for surveys focused on the vertical integration decision including the property rights theory of the firm.
} 
integration is used to reduce inefficiencies that arise due to incomplete contracting. In Grossman and Hart (1986), for example, two parties make non-contractible investments ex ante while utility is non-transferable. They show that one party purchases the other's assets whenever the former's investment is more important than the latter's.

A related study by Aghion and Tirole (1994) employs the incomplete contracting framework to examine the organization of innovation. In their analysis, the firm's key choices are R\&D efforts and financing. The results suggest that when R\&D efforts are more important, $\mathrm{R} \& \mathrm{D}$ is more likely to be conducted by an independent unit, while financing being more important yields the opposite. Lerner and Merges (1998) study the determinants of control rights in biotechnology alliances, and find results consistent with Aghion and Tirole's theory.

We also employ an incomplete contracting assumption and ex ante investments to analyze integration decisions concerning R\&D investments. In our model, the choice to vertically integrate means that the originating firm conducts $R \& D$ in-house and maintains control over investment decisions that influence the location of the new product in product space, while outsourcing means the originating firm loses the ability to influence the new product's location in product space. An important difference between our model and previous papers in this literature concerns the manner in which investment outcomes depend on which party has control rights. In Grossman and Hart (1986) and Aghion and Tirole (1994), firms have different investment technologies and the firm with the superior technology purchases the assets of the other firm. In contrast, in our model all firms have access to the same investment technology, and the key element is that the originator has higher investment incentives because of the potential cannibalization of other products in the originator's product portfolio. $^{8}$

This paper also contributes to the mostly empirical literature that relates vertical integration with product market competition. A number of early studies such as Tucker and Wilder (1977), Levy (1985), and Balakrishnan and Wernerfelt (1986) focus on US manufacturing and find a positive correlation between vertical integration and product market competition. More recently, Galdon-Sanchez et al. (2015) concerning services and Gil and Ruzzier (2018) focusing on the Spanish television industry find a negative relationship which stands in contrast to most of the earlier studies. We develop a theory that predicts a negative relationship between competition and the frequency of in-house $R \& D$, in which the negative relationship is due to reduced incentives for in-house development when the originator owns an existing patented product in the same product class as the product under development. We also

\footnotetext{
${ }^{8}$ An implicit assumption, which is important for this result, is that the originator can not sell related products in its product portfolio to an outsourcing firm. One reason such a strategy might not be feasible is the existence of private information on the part of the originator concerning the value of related products, and the resulting adverse selection problem as in Akerlof (1970) which prohibits the possibility of trade.
} 
provide empirical testing using pharmaceutical data that strongly supports the predicted relationship. ${ }^{9}$

Several papers analyze the ability of firms to limit cannibalization when introducing a new product. Moorthy and Png (1992) show that, when consumers are impatient, a monopolist selling a product line can sometimes increase its profitability by delaying the introduction of a lower quality product which allows the firm to increase the price of a higher quality product. In Siebert (2015) a firm's optimal strategy in entering a new market in a duopoly setting with vertical differentiation is to introduce a single product. This result arises when avoiding cannibalization is more important in their setting than price discrimination. The literature on planned obsolescence in which renting is used to avoid time inconsistency concerning new product introductions such as Waldman (1993, 1996), Choi (1994) and Nahm (2004) is also closely related. We contribute to this literature by showing how the desire to limit cannibalization can affect the internal organization of the firm.

Finally, most of the prior literature on the issue of firm boundaries in the pharmaceutical industry has focused either on why firms form alliances, or the outcomes of alliances. Nicholson et al. (2005) shows that biotech companies send positive signals to investors by forming alliances with larger pharmaceutical firms, while Danzon et al. (2005) finds that success rates of complex phase II and phase III trials are higher for products developed in an alliance. Few papers focus on the characteristics of $R \& D$ projects that tend to result in in-house development rather than outsourcing. One such paper is Azoulay (2004) which finds that pharmaceutical firms are more likely to outsource data-intensive clinical trials, while knowledge-intensive trials are typically conducted in-house. Our paper is the first to offer a patent protection perspective on the choice of pharmaceutical alliance decisions at the project level.

\section{Model and Preliminary Analysis}

In this section, we present a T-period model of a firm's decision to conduct R\&D either inhouse or through outsourcing. We then provide preliminary results concerning R\&D decisions made given the firm chooses in-house development, and when it chooses to outsource. In the next section, we provide a full equilibrium analysis, and also derive testable predictions.

\footnotetext{
${ }^{9}$ There is also a related literature concerning the correlation between product market competition and the magnitude of R\&D investments. For example, Aghion et al. (2005) find a U-shaped relationship using UK manufacturing data. Our model does not directly address this issue, although we believe an extension of the model would generate a positive relationship when firms own patents in the same product class.
} 


\subsection{The Model}

In our model, there is a single risk neutral firm that owns an existing patented product, and has decided to develop a new product in the same product class. We call this firm the originator. The originator exhibits a constant marginal cost $c_{1}$ for producing a unit of its existing patented product and no fixed costs. There are also generic producers that can produce the existing patented product at marginal cost $c_{1}$ and no fixed costs after patent expiration.

In addition to the originator and the generic producers, there is a pool of identical risk neutral in-licensing firms that we refer to as the licensees. The licensees command a potential cost advantage in developing the new product in comparison to the originator. ${ }^{10}$ In particular, the originator has a fixed cost of development $F_{O}$ which is a random draw from the probability density function $f(\cdot)$ with support $\left(F_{\min }, \infty\right)$, while the licensees incur a fixed cost of development $F_{L}$,

$$
F_{\min } \leq F_{L}<\infty
$$

We use $\Delta$ to refer to the difference in fixed costs, i.e., the originator's disadvantage relative to the licensees

$$
\Delta=F_{O}-F_{L}
$$

We further assume that the marginal cost of production for the new product is lower for the firm that develops the product. Specifically, the developer has a marginal cost of production for the new product equal to $c_{2}$, while the marginal cost of production for a firm that did not develop the new product is $c_{2}^{+}>c_{2}$. In other words, there are economies of scope between developing and producing the new product.

We assume that there are $T$ total periods, $T \geq 4$, with the new product being developed in period two and the patent for the new product lasting through period $T$. The patent on the existing product, on the other hand, expires at the end of period $t_{E}$, where $t_{E}$ can take on any value between one and $T$. Much of our focus is how behavior changes as a function of $t_{E}$. To simplify exposition, we assume no discounting.

If the originator chooses in-house development, it develops the new product, chooses the new product price each period, and produces and sells the new product each period. ${ }^{11}$ If

\footnotetext{
${ }^{10}$ In the case of the pharmaceutical industry, which is the industry we focus on in the empirical analysis, the cost advantage could stem from greater experience conducting randomized control clinical trials and interacting with the Food and Drug Administration, the key regulatory body in the pharmaceutical context.

${ }^{11}$ We do not allow for a contract that would assign production, selling, and pricing decisions to another firm when the originator chooses in-house development. Given the originator is as efficient or more efficient than other firms in these activities when the originator chooses in-house development, allowing for such a contract would not change the equilibrium outcome.
} 
the originator chooses to outsource development, on the other hand, then there is a contract between the originator and the licensee. ${ }^{12}$ The contract specifies for each period who produces the product, who sells the product (the firm that sells the product is the firm that receives payments from the consumers), who chooses the new product price each period, and a payment each period from the originator to the licensee which can depend on that period's new product quantity (the payment can be negative). ${ }^{13}$

We also assume the contract to be renegotiation-proof. This assumption is described in more detail below. Furthermore, actions and outcomes associated with the development process itself are assumed to be non-verifiable and thus non-contractible. This means that, in case the originator chooses in-house development, then it makes all the choices associated with the development process. But if outsourcing is chosen, then the licensee makes these choices, and payments cannot be directly contingent on these choices. ${ }^{14}$

Following Salop (1979), the product space is characterized by a unit circle, in which the location of the new product on the unit circle depends on the non-contractible development decisions. That is, the firm developing the new product (either originator or licensee) makes choices that serve to determine the location of the new product relative to the existing patented product. Due to the stochastic nature of the development process, however, the developer does not directly control the location of the new product but instead chooses a mean value for the location, $l_{M}$, and an investment level, $k$, that determines the expected absolute distance between the mean location and the realized location.

To be precise, the clockwise distance between the new product and the existing patented product on the unit circle is given by

$$
l=l_{M}+\varepsilon
$$

where $\varepsilon$ is a random draw from one of the following two uniform distributions:

$$
U[-\alpha, \alpha] \text { and } U[-\beta, \beta], \quad \alpha<\beta \leq \frac{1}{4} \cdot{ }^{15}
$$

\footnotetext{
${ }^{12}$ In our empirical analysis focused on the pharmaceutical industry, the development decisions we investigate that can be conducted in-house or outsourced are Preclinical and Phases I through III clinical trials. See Section 5 for further discussion.

${ }^{13}$ Implicitly, we are assuming that the new product price is non-verifiable and thus not contractible. This assumption is not essential for our main results, but rather serves to simplify the analysis. We also assume that the payment from the originator to the licensee in any period $t$ cannot depend on the new product quantity in a different period. This assumption is also not essential for our main qualitative results, but also serves to simplify the description of equilibrium behavior.

${ }^{14}$ See Casas-Arce et al. (2019) for a recent related analysis in which details of the development process are left incomplete in a setting in which renegotiation is possible. These authors point out that this approach is consistent with commonly observed contracting practices in R\&D intensive industries.

${ }^{15}$ The assumption $\beta \leq \frac{1}{4}$ is imposed for tractability reasons. It ensures that, after the patent on the old
} 
A higher investment level translates into a higher probability the random draw is from the uniform distribution with the smaller range. Let $p(k)$ denote the probability that $\varepsilon$ is drawn from $U[-\alpha, \alpha]$ given the investment level equals $k$. We assume that $p(\cdot)$ is continuously differentiable, $p(0)=0, p^{\prime}(0)=\infty, p^{\prime}(k)>0$ and $p^{\prime \prime}(k)<0$ for all $k \geq 0$, and $p(\infty)<1$.

On the demand side, there is a continuum of consumers of unit mass uniformly distributed along the circumference of the circle. A consumer can buy any weakly positive number of one of the products, i.e., a consumer can buy units of the originator's existing patented product or units of the new product, but we do not allow mixing. ${ }^{16}$ To be precise, the valuation a consumer places on consuming unit $q$ of a product is given by

$$
V(q)=V^{+}-v q
$$

so the valuation function is characterized by decreasing marginal utility of consumption. A consumer also faces a distance cost for consuming a product not at the consumer's exact location in product space. The distance cost a consumer incurs from consuming a unit located a distance $s$ from the consumer's location in product space equals $d s, d>0$. We also assume $V^{+}$to be sufficiently large such that the market is always fully covered in equilibrium. For any product price, $P$, a consumer who chooses to buy that product purchases the amount that maximizes net utility from consumption, i.e., the consumer chooses the value for $Q$ that maximizes

$$
\int_{0}^{Q}\left(V^{+}-v q\right) d q-(P+d s) Q .
$$

In turn, in facing prices for the two products, a consumer chooses to purchase the product that results in the highest net utility for the consumer given the quantity choices that maximize net utility. ${ }^{17}$

The timing of the game is as follows. At the beginning of the first period, the originator chooses a price for the existing patented product for the first period, consumers make purchase decisions, and the value for $F_{O}$ is realized and publicly revealed. ${ }^{18}$ In the first period, the originator also decides whether to develop the new product in-house or outsource devel-

product expires, some consumers on both "sides" of the new product continue to purchase the new product.

${ }^{16}$ The assumption that there is no mixing is consistent with typical demand behavior in the pharmaceutical industry. For example, individuals treated for depression seldom take different anti-depressant drugs at the same time due to concerns of possible unwanted drug interactions.

${ }^{17}$ An alternative theoretical approach is to assume that each consumer purchases zero or one unit of the product that provides the consumer with the highest net utility, but that there are multiple consumers in each location whose valuations are uniformly distributed over $\left[0, V^{+}\right]$. This alternative specification is mathematically equivalent to the specification we analyze.

${ }^{18}$ The assumption that the realization of $F_{0}$ is publicly revealed is not essential for our results. In particular, results would be the same without this assumption if we focused on Perfect Bayesian equilibrium rather than Subgame Perfect Nash equilibrium. 
opment to a licensee. If the originator chooses to outsource, then the first period proceeds with a contracting stage. In particular, each firm in the pool of licensees makes a take-it or leave-it offer of a licensing contract to the originator and the originator chooses a licensee. ${ }^{19}$

At the beginning of the second period, the originator chooses a second period price for the existing patented product and consumers again make purchase decisions. If the patent has not expired, then the originator sets the monopoly price, while it if has expired then competition with generic producers means the price equals marginal cost equal to $c_{1}$. The developer (either originator or licensee) also chooses a mean value for the new product's location in product space and an investment level in location precision. These choices are private information of the developer. After these choices have been made, the noise term is drawn from the respective uniform distribution. Thus, by the end of the second period the new product's location in product space is determined. We assume this location to be publicly observable but not verifiable by the courts.

In the third period, the new product is brought to the market. In case the patent on the existing product expires before the third period, then the price for the existing product is at marginal cost and the firm with control rights for the pricing of the new product takes this price as given when choosing a price for the new product. If the patent on the existing patented product has not expired, then the originator chooses prices for both products if it has control rights for the pricing of the new product. On the other hand, if the patent on the existing patented product has not expired and the licensee has the control rights, then the two prices are determined by Bertrand competition between the two firms. In the following periods, prices are determined using the same rules as in the third period. Also, our focus throughout is Subgame Perfect Nash equilibrium.

As mentioned above, we restrict our analysis to contracts that are renegotiation-proof. ${ }^{20}$ This means that the contract between the originator and the licensee must be such that, in every period starting with period two, the parties do not have an incentive to renegotiate. To be specific, at the beginning of each period starting with period two, if the originator (licensee) makes a take-it or leave-it offer of a new contract to the licensee (originator), the equilibrium contract is such that the licensee (originator) has at least a weak incentive to turn down any offer that would make the originator (licensee) better off. That is, the equilibrium contract is such that no Pareto-improving renegotiation outcome exists.

\footnotetext{
${ }^{19}$ We assume that each firm in the pool of licensees either works as the developer of the originator's new product, or develops no new product. We thus abstract away from the possibility of cross-subsidization which is the focus of Lerner and Malmendier (2010).

${ }^{20}$ Focusing on renegotiation-proof contracts is a standard approach employed in many contracting papers. For early papers that focus on how the possibility of renegotiation affects equilibrium contracting see, for example, Dewatripont (1988), Hart and Moore (1988), and Demougin (1989).
} 


\subsection{Preliminary Results}

We start with results concerning the nature of the equilibrium contract when the originator chooses to outsource. As captured in Lemma 1 below, production, sales, and pricing are all assigned to the licensee in every period after patent expiration of the existing product. In contrast, prior to patent expiration of the existing product, production is assigned to the licensee, but sales and control rights for pricing remain in the hands of the originator.

Lemma 1 Consider an equilibrium to the game in which the originator has chosen to outsource development of the new product. Then, the contract between the originator and the licensee satisfies i) through iii).

i) In any period $t, 2<t \leq t_{E}$, the contract assigns production to the licensee, but sales and control rights for pricing of the new product remain with the originator. Also, the payment from the originator to the licensee is a fixed amount plus the number of new units sold that period multiplied by $c_{1}$.

ii) In any period $t, t>\max \left\{2, t_{E}\right\}$, the contract assigns production, sales, and pricing of the new product to the licensee. Also, the payment from the originator to the licensee is a fixed amount.

iii) The fixed payments from the originator to the licensee sum to the fixed amount that results in zero expected profits for the licensee.

The logic for part i) is as follows. First, the licensee is assigned production of the new product, because outsourcing only occurs when the licensee has a lower cost of development. Second, in any period prior to patent expiration of the existing patented product, the joint profits of the originator and licensee are maximized by giving sales and the control rights over pricing to the originator, so that it can choose prices that maximize the joint profits of the two products. Given the contract is renegotiation-proof, this means that sales and control rights for the pricing decision must be assigned to the originator. Also, having the payment from the originator to the licensee be a fixed amount plus the number of new units sold multiplied by $c_{2}$ means higher joint profits, because in choosing prices the originator will internalize all the returns associated with the pricing decisions.

Now consider a period after patent expiration of the existing product. If the contract assigns production, sales, and pricing to the licensee, the contract will not be renegotiated because the licensee can set the price just as effectively as the originator after patent expiration. In turn, since assigning sales and the pricing decision to the licensee increases the licensee's investment incentives, this is the equilibrium outcome. Also, the payment from the originator to the licensee is a fixed amount, so that the licensee internalizes all of the 
effects of its pricing decision. Finally, iii) follows given competition across licensees ensures a zero expected profit condition on the part of the licensee.

The next step is to consider decisions concerning new product location. Let $L\left(j, t_{E}\right)$ denote the mean distance between the new product and the existing patented product as a function of whether development is in-house, $j=I$, or outsourced, $j=O$, and the period of patent expiration, $t_{E}=2, \ldots, T$. Similarly, $K\left(j, t_{E}\right)$ is the investment in location precision as a function of whether development is in-house or outsourced and the period of patent expiration.

Lemma 2 Holding all parameters fixed, if the in-house versus outsource decsion is taken as given, then i) through $v)$ describe $L\left(j, t_{E}\right)$ and $K\left(j, t_{E}\right)$.
i) $L\left(I, t_{E}\right)=L\left(O, t_{E}\right)=\frac{1}{2}$ for all $t_{E}, t_{E}=2, \ldots, T$.
ii) $K(I, 1)=K(I, 2)=K(O, 1)=K(O, 2)$.
iii) $K\left(I, t_{E}\right)>K\left(O, t_{E}\right)$ for all $t_{E}>2$ and $K(O, T)=0$.
iv) $K(I, T)>K(I, T-1)>\ldots>K(I, 2)=K(I, 1)$.
v) $K(O, 1)=K(O, 2)>K(O, 3)>\ldots>K(O, T)=0$.

Consider first what happens when the originator chooses in-house development. Clearly, for any value of $t_{E}$ profits are maximized when the new product's location is exactly half way around the unit circle from the location of the existing patented product. So $L\left(I, t_{E}\right)=\frac{1}{2}$ for all $t_{E}, t_{E}=1,2, \ldots, T$. Now consider the investment in location precision. The firm's return to having the new product's location close to the mean location is higher prior to patent expiration, because the firm is choosing two prices. So the investment level increases the later is patent expiration of the existing patented product, i.e.,

$$
K(I, T)>K(I, T-1)>\ldots>K(I, 2)=K(I, 1) .
$$

Suppose the originator opts for outsourcing and $t_{E}=T$. In this case, in each of periods 3 through $T$ which are after the new product's location has been determined, joint surplus is maximized if the originator receives the returns associated with new product sales and has control rights over the pricing decision. So that is what is specified in the contract given our focus on renegotiation-proof contracts. In turn, this means that the licensee has no incentive to invest in location precision, so $L(I, T)=L(O, T)=\frac{1}{2}$ and $K(I, T)>K(O, T)=0$. Note that the mean location specified in the contact is still $\frac{1}{2}$ since this improves joint surplus.

Finally, suppose that the originator chooses outsourcing and $2<t_{E}<T$. Because the contract must be renegotiation-proof and the patent is still valid for sales of the existing patented product up through period $t_{E}$, sales and control rights for pricing the new product 
reside with the originator up through $t_{E}$. In contrast, after period $t_{E}$, the patent has expired with the result that sales and control rights for pricing the new product reside with the licensee. The result is that the licensee's incentive to invest is higher than when $t_{E}=T$, but lower than when $t_{E}=1$ or 2 , and in this range the incentive to invest falls with $t_{E}$, i.e.,

$$
K(O, 1)=K(O, 2)>K(O, 3)>\ldots>K(O, T)=0 .
$$

Also, the incentive to invest is less than under in-house development, i.e., $K\left(O, t_{E}\right)<$ $K\left(I, t_{E}\right)$ given $2<t_{E}<T$, since with in-house development the developer in every period sells the product, has pricing control rights, and therefore internalizes all the returns associated with the pricing decisions. Lastly, similar to the other cases, $L\left(O, t_{E}\right)=\frac{1}{2}$ given $2<t_{E}<T$.

\section{Equilibrium Analysis and Testable Predictions}

This section starts with a characterization of the in-house versus outsourcing decision and then presents our testable predictions.

\subsection{Equilibrium Analysis}

The focus of our analysis is the originator's choice concerning whether to conduct development in-house or to choose outsourcing. The potential benefit to outsourcing is that the fixed cost of development is lower by the amount $\Delta$. The cost of outsourcing is that, as shown in the previous section, the expected investment in location precision is lower if $t_{E}>2$, and this serves to lower originator profits because the expected distance in product space between the new product and the existing patented product is smaller. A comparison of this benefit and cost determines whether the originator chooses in-house development or outsourcing.

In the analysis that follows, our focus is the originator's choice of in-house development versus outsourcing as a function of the difference in fixed costs associated with in-house development. Proposition 1 below captures that there is a critical value for this difference, call it $\Delta^{*}, \Delta^{*}>0$, such that the originator chooses in-house development when $\Delta \leq \Delta^{*}$ and outsourcing otherwise. ${ }^{21}$ The straightforward logic for this result is that in-house development is chosen when this choice is associated with a cost advantage or small disadvantage,

\footnotetext{
${ }^{21}$ To simplify the exposition, we assume that the originator chooses in-house development whenever it is indifferent between the two choices.
} 
while outsourcing is chosen when there is a large disadvantage associated with in-house development. The proposition also captures additional results which we discuss below.

Proposition 1 Holding all other parameters fixed, there exists a value $\Delta^{*}$ such that the originator chooses in-house development when $\Delta \leq \Delta^{*}$ and chooses outsourcing otherwise, where $\Delta^{*}$ is a strictly increasing function of $t_{E}$ for $t_{E} \geq 2$ and equals 0 if $t_{E}=1$ or 2 . Also, equilibrium behavior satisfies results in Lemmas 1 and 2, where the equilibrium contract given $\Delta>\Delta^{*}$ is unique up to the timing of the payments described in Lemma 1.

Consider first $t_{E}=1$ or 2 . In these cases, the patent on the existing product expires before the new product reaches the market. As found in the previous section, when this is the case there is no advantage in terms of investments in location precision from choosing in-house development. This means the investment in location precision is independent of whether the originator chooses in-house development or outsources. So this choice depends solely on which of the two options has lower fixed costs associated with the development process, i.e., $\Delta^{*}=0$ in this case.

Now consider what happens when $t_{E}>2$. From the analysis in the previous section, we know that for these parameterizations a licensee's incentive to invest in location precision is less than the originator's incentive to invest given in-house development. Given this advantage associated with in-house development, the originator will only choose outsourcing if there is a sufficiently large reduction in the fixed cost of development associated with outsourcing, i.e., $\Delta^{*}>0$ if $t_{E}>2$.

Now consider two values for $t_{E}, t^{\prime}$ and $t^{\prime}+1$, where $t^{\prime} \geq 2$. From the analysis in the previous section, we know that the investment in location precision increases with $t_{E}$ given in-house development, while it decreases with $t_{E}$ given outsourcing. In other words, the expected loss due to a lower investment in location precision when the originator chooses outsourcing is higher when $t_{E}=t^{\prime}+1$. So the reduction in fixed costs associated with outsourcing required for the originator to make that choice must be higher when $t_{E}=t^{\prime}+1$, i.e., $\Delta^{*}$ increases in $t_{E}$.

\subsection{Testable predictions}

We now discuss testable predictions of our theory. The first two testable predictions follow immediately from results stated in Proposition 1.

Testable Prediction 1 A firm developing a new product has a higher probability of choosing in-house development if it sells an existing patented product in the same product class, and the new product is expected to reach the market before this patent expires. 
Testable Prediction 1 follows from Proposition 1, i.e., $\Delta^{*}=0$ given $t_{E}=1$ or 2 and $\Delta^{*}>0$ for all $t_{E}>2$. Recall that $\Delta^{*}$ determines the probability that in-house development is chosen, with a higher value for $\Delta^{*}$ translating into a higher probability that the choice is in-house development. Proposition 1 says that when $t_{E}=1$ or 2 , i.e., at the time the new product reaches the market the patent on the existing product will have expired, that $\Delta^{*}=0$. In other words, in this case the in-house versus outsource decision is determined solely by which choice results in lower costs. If $t_{E}>2$, however, i.e., the patent on the existing patented product will be valid at the date the new product reaches the market, then $\Delta^{*}>0$ which means that outsourcing is only chosen if it is associated with a meaningful cost advantage.

Testable Prediction 2 Consider a firm developing a new product that owns an existing patented product in the same product class. The longer this patent is expected to be valid after the new product reaches the market, the higher is the probability the firm chooses inhouse development.

Testable Prediction 2 is the Proposition 1 result that $\Delta^{*}$ increases with an increase in $t_{E}$. As before, $\Delta^{*}$ determines the probability of in-house development. A higher value for $\Delta^{*}$ means a higher probability of in-house development. The proposition states that an increase in $t_{E}$ increases $\Delta^{*}$, with the underlying logic being that an increase in $t_{E}$ raises investment incentives given in-house development, but does not given outsourcing. Thus, the underinvestment given outsourcing rises with an increase in $t_{E}$, which means the fixed cost reduction associated with outsourcing needed for outsourcing to be chosen is higher. This is equivalent to saying that when the patent on the existing patented product is expected to be valid for a longer period of time after the new product reaches the market, i.e., $t_{E}$ increases, $\Delta^{*}$ rises which translates into a higher probability of in-house development.

The third prediction concerns market share. In our base model, the originator is a monopolist in the product class. Suppose that, however, rather than being a monopolist, the originator was one of a small number of firms selling products in the product class. In this case, the return to the originator of increased location precision would be positively related to the market share of the firm's existing patented products at the date the new product would reach the market. If this share was low, then cannibalization would be mostly in terms of other firms' patented products and sales of products not under patent protection, so the firm's incentive to control product location of the new product would be low. But if the share was high, then the firm's incentive to control product location of the new product would be high because the return to avoid cannibalization of its own patented products would be high. This logic leads to our third testable prediction. In Appendix B we extend 
our formal base model to include competition. This allows us to derive results as a function of the originator's market share before the introduction of the new product. $^{22}$

Testable Prediction 3 Consider a firm developing a new product that sells existing patented products for which the patents are scheduled to expire after the new product reaches the market. The probability of in-house development will be higher the larger is the predicted market share of the firm's existing patented products at the date of the new product's introduction.

One way to think about this prediction is to focus on the two returns to location precision in our argument. One return is that by reducing the expected deviation between the realized location of the new product in product space and the optimal location, the firm increases the profitability of the new product The second is that by reducing this expected deviation, it also increases the profitability of its existing patented products prior to the expiration of those patents. Increasing the market share of the existing patented products in the product class makes the second factor more important, which means an increase in the returns to improved product location. When that market share is higher, we expect a higher probability of inhouse development, since in-house development increases investments in location precision.

A final point concerning testable predictions concerns the relationship between the model and the data. In the model, there is a single in-house versus outsource development decision for each product. In the data, in contrast, products are associated with multiple R\&D investments, each of which can be conducted either in-house or outsourced. With this in mind, in Appendix B we extend the model to allow for multiple R\&D investments for a single product and show that the testable predictions hold for each development decision in this extension of our analysis. ${ }^{23}$

\section{Data from the Pharmaceutical Industry}

The pharmaceutical industry is an excellent setting in which to test our theory for a number of reasons. First, the industry spends a substantial amount on R\&D for the development of new drugs each year. Second, the industry heavily relies on patents, i.e., it is possible to measure variation in the cost of cannibalization. Third, uncertainty in the development

\footnotetext{
${ }^{22}$ In our generalized setting, the originator competes with a rival in a product space defined as a triangle that is homeomorphic to a circle but lends itself more easily to an interpretation of innovation under competition.

${ }^{23}$ To be precise, in this extension we show that our first two testable predictions hold for each R\&D investment in our multiple investment extension. Although we do not include such an analysis, we could also formally show that the third prediction is also true by combining our first extension concerning incorporating a rival with our second extension concerning multiple R\&D investments.
} 
process implies that the pharmaceutical industry is a prime example of an environment in which firms cannot perfectly control the exact location of new products in product space. For example, the types of patients recruited for clinical trials, and how well the drug works on those patients will affect the FDA-approved label, and pharmaceutical firms can only market "on-label." Fourth, it is common practice at pharmaceutical firms to develop some new drugs in-house, while outsourcing the development of others. This suggests sufficient variability concerning the in-house versus outsource decision to test our theory. ${ }^{24}$

\subsection{Main Data Source and Descriptive Statistics}

Our principal data source is the Pharmaprojects dataset. This dataset was assembled by the company Informa and contains information concerning the development of new pharmaceutical projects throughout the world. The dataset covers information for the time period 1989 through 2004. For each chemical compound under development, the dataset contains the name of its originator, the therapeutic class, active ingredients, patent number and its filing date, if any, whether development was outsourced and, if so, the names of the licensees, and the beginning and end dates of licenses and development stages.

A key issue for our empirical analysis is defining whether development decisions are in-house versus outsourced. In particular, whether a development decision is in-house or outsourced depends on whether the originator ever signs a licensing contract and, if it did, the stage of the development process at which the earliest development decision was signed..$^{25}$ Clearly, if there was never a licensing contract, then all development decisions are in-house which is how we categorize them. On the other hand, if there was a license at some point in the development process, we categorize decisions made prior to the license as in-house, and those made after the first license as outsourced. ${ }^{26}$ Below we provide additional detail concerning this classification process.

\footnotetext{
${ }^{24}$ See Lakdawalla (2018) for a survey of the literature on the pharmaceutical industry focused primarily on innovation, pricing, and marketing decisions.

${ }^{25}$ Note that when two firms merge, our main dataset updates the company name of the originator of the compound to the name of the acquiring firm. For example, if Warner-Lambert was the originator of compound $X$ in 1997 and was acquired by Pfizer in 1999, then in our main dataset it is possible that WarnerLambert would not be identified as the originator which could create misclassification if there was a licensing contract between Warner-Lamber and Pfizer prior to 1999. We compiled a list of mergers and acquisitions and assigned compounds to the correct originating firms to avoid any statistical problems related to such misclassification.

${ }^{26}$ In our theoretical approach, when a development decision is outsourced, the originator does not retain control rights concerning the pricing of the new product. Given this, investment incentives for subsequent development decisions would be independent of whether the R\&D is in-house or outsourced. This suggests that, from the standpoint of investment incentives, having one decision outsourced is equivalent to having that decision and all subsequent decisions outsourced. So we categorize all decisions made after the first license as outsourced independent of who conducts the R\&D.
} 
Table C.1 presents a summary of the development phases as described by the FDA. Preclinical consists mostly of tests on laboratory animals, while phase I focuses on safety and phase II on effectiveness and side effects. Both phase I and phase II are typically conducted on a relatively small scale, with the former recruiting around 20 to 80 subjects and the latter between a few dozen and about 300 subjects. Phase III continues testing on safety and effectiveness employing a much larger sample, usually ranging from several hundred to 3,000. Conceivably, a developer could affect a new drug's location in product space during phase III by recruiting specific patient population groups and testing for specific efficacy measures and side effects. However, in most cases, once phase II is completed and the FDA meets with the developer to discuss plans for phase III, it becomes quite difficult for the developer to make significant changes that would affect the new drug's expected location in product space.

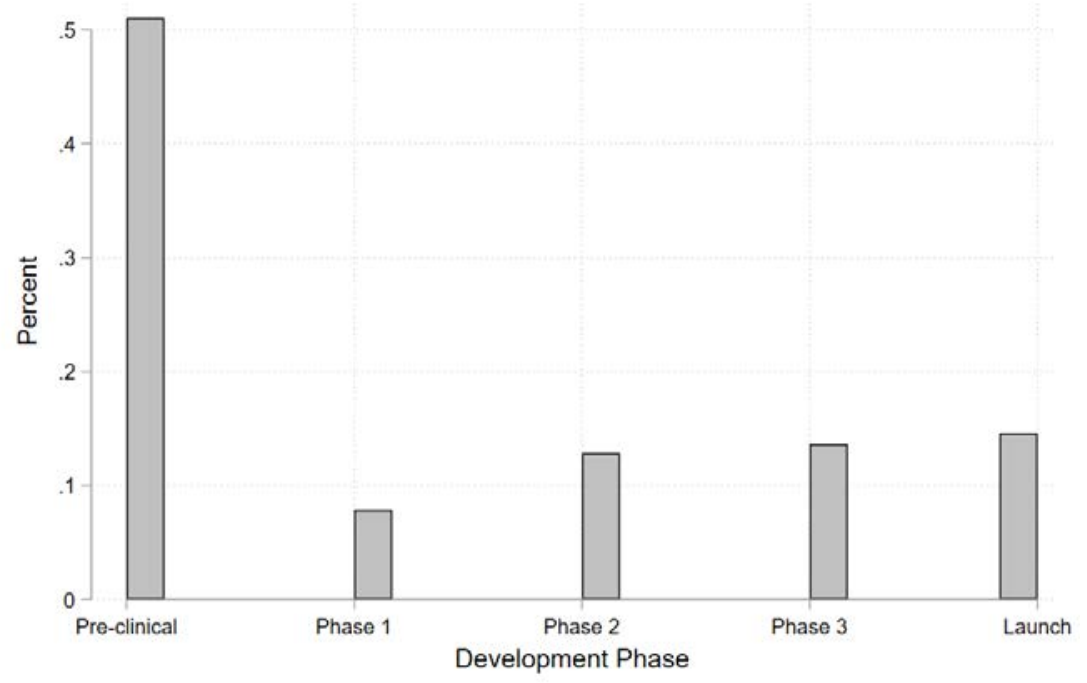

Figure 1: Distribution of the Earliest Licensing Deal by Development Phase

With this in mind, in our main analysis we assume all development decisions occur prior to the beginning of phase III. More specifically, our focus is drug-compound years prior to the beginning of phase III, where drug-compound years that are prior to the first license are classified as in-house observations, while drug-compound years that are after the first license are classified as outsourced. Restricting focus to compounds for which there was at least one drug development license, the initial license occurred during pre-clinical testing in 51.4 percent of the cases, during phase I in 7.9 percent of the cases, during phase II in 12.8 percent of the cases, during phase III in 13.6 percent of the cases, and in 14.6 percent of the cases the first license was only agreed to after the product was launched. See Figure 1 for a graphic illustration. 
We construct three measures of whether the originator of a new product owns existing patented products in the same product class. The first measure, which we call EOP1, is an indicator variable that takes on a value of one if the originator owns one or more other patented products in the same product class and a value of zero otherwise. ${ }^{27}$ The second measure, which we call EOP2, equals the number of other patented products owned by the originator which are in the same product class. With a third measure, called EOP3, we distinguish between existing patents in later development stages from those in earlier stages. Our goal is to construct a measure of the expected number of other patented compounds in the same product class owned by the originator that will eventually reach the market. Following Higgins and Rodriguez (2006), we construct EOP3 using a count of same-class same-firm patented compounds weighted by the the probability of becoming an approved drug conditional on the current stage of development. Based on existing research, the probabilities are 0.08 for pre-clinical, 0.20 for phase I, 0.28 for phase II, 0.58 for phase III, and 1.0 for launched drugs.

We also employ patent length variables. The first patent length variable, called LOP1, is the remaining length of the patent with the largest remaining length of all the patents owned by the same firm which are in the same class as the drug under development. The second patent length variable, LOP2, is the sum of the remaining patent lengths of all the drugs in the same product class owned by the same firm as the drug under development. The third patent length variable, LOP3, is the weighted sum of the remaining patent lengths for all the drugs in the same product class owned by the same firm as the drug under development, where the weights are based on the probabilities that drugs still under development reach the market as a function of the current stage of development.

One potential alternative explanation for how an originator chooses between in-house development and outsourcing is that it chooses to develop a drug in-house when it has a relatively large amount of experience. ${ }^{28}$ In some of our empirical tests, we thus control for an originator's prior experience in developing drugs in the product class of the current drug under development. We define class-specific experience as the sum of the compound-year observations within a firm's particular therapeutic class up to the current year. Including this variable in our tests allows us to separate the cost-side explanation for the in-house versus outsource decision from our explanation which concerns investment incentives.

\footnotetext{
${ }^{27}$ According to the Pharmaprojects Therapeutic Class Codes, there are 17 broadly defined categories. These categories are alimentary/metabolic products, blood and clotting products, cardiovascular products, dermatological products, formulations, genitourinary products, hormonal products, immunological products, anti-infective products, anticancer products, musculoskeletal products, neurological products, anti-parasitic products, respiratory products, sensory products, biotechnology products, and miscellaneous products.

${ }^{28}$ See, for example, Pisano (1990) for empirical evidence that experience is an important determinant of whether firms choose in-house development or outsourcing.
} 
In addition to class-specific experience, in some of our tests we also include a measure of economies of scope as another cost-side control. Following Danzon et al. (2005), we construct a Herfindahl Hirschman Index (HHI) for each firm's therapeutic scope by summing the squares of the percentage of compounds being developed for each therapeutic class within a firm in a given year. The bigger the value of the HHI, the more concentrated is the firm's development portfolio in terms of therapeutic class. One might hypothesize that economies of scope arise when the development portfolios are less concentrated, and so a lower HHI should be associated with a higher probability of in-house development.

We also construct two variables that capture market-level variability in a firm's incentive to avoid cannibalization. The first variable, PDM, is the number of patented drugs on the market that are in the same therapeutic class as the drug under development, but which are owned by firms other than the originator of the drug under development. The second variable, TDM, is the total number of drugs on the market that are in the same therapeutic class as the drug under development. The purpose of including these two variables is to control for the possibility that an increase in the number of competing drugs on the market, holding fixed the total number of drugs on the market, lowers the incentive for the originator to avoid cannibalization. Table C.2 provides a full list of our constructed variables along with their definitions.

Table C.3 reports descriptive statistics for the development decision and patent data. The sample used in the main analysis contains 64,505 compounds originated between 1989 and 2004. On the compound-year level, 81.0 percent of the observations are classified as in-house development. The data for the first patent existence measure, EOP1, shows that in 74.9 percent of the compound-year observations characterized by in-house development and 59.4 percent of the observations characterized by outsourcing, the originator owned at least one other patented compound in the same product class. In addition, compared to compoundyear observations characterized by outsourcing, in-house observations have a higher number of other patented compounds in the same product class owned by the originators (EOP2), as well as a higher expected number of other patented compounds owned by the originators that are in the same product class and that are expected to reach the market (EOP3).

Table 1 shows how in-house development varies across the therapeutic classes in our dataset. In most cases the percentage of observations classififed as in-house development is reasonably close to the percentage in the full sample. However, for the antiparasitic therapeutic area in-house development is substantially more common than in the overall sample, while in-house development is substantially less common in the biotechnology area than in the overall sample. 
Table 1: Distribution of In-house Development Across Broad Therapeutic Areas 1989-2004

\begin{tabular}{lccc}
\hline \hline & Mean & Std.Dev & Count \\
\hline alimentary/metabolic & 0.838 & 0.369 & 3623 \\
blood and clotting & 0.875 & 0.331 & 2593 \\
cardiovascular & 0.889 & 0.315 & 6262 \\
dermatological & 0.761 & 0.426 & 1261 \\
formulations & 0.703 & 0.457 & 7914 \\
genitourinary & 0.814 & 0.390 & 1320 \\
hormonal products & 0.804 & 0.397 & 632 \\
immunological & 0.774 & 0.419 & 1772 \\
anti-infective & 0.853 & 0.354 & 9552 \\
anticancer & 0.803 & 0.397 & 7849 \\
musculoskeletal & 0.838 & 0.368 & 4021 \\
neurological & 0.888 & 0.315 & 9464 \\
antiparasitic & 0.966 & 0.182 & 264 \\
respiratory & 0.869 & 0.338 & 2594 \\
sensory & 0.844 & 0.363 & 410 \\
biotechnology & 0.642 & 0.479 & 13138 \\
miscellaneous & 0.656 & 0.475 & 948 \\
\hline Observations & 73617 & & \\
\hline \hline
\end{tabular}

\subsection{Secondary Data and Descriptive Statistics}

To supplement the analysis, we also use the IMS dataset to create a market share measure based on drug sales. The IMS data includes a list of all drugs and their annual sales in the US between 1992 and 2004. The sales data are merged into the principal dataset from Pharmaprojects based on the name of the drug, its therapeutic class, as well as whether the drug is branded or not (i.e., generic). Because the IMS dataset classifies drugs according to the Anatomical Therapeutic Chemical (ATC) system which differs somewhat from the classification system used in the Pharmaprojects dataset, the tests that employ our market share measure only focus on the drug classes that are common to both classification systems. ${ }^{29}$ We calculate for each drug under development in the principal dataset the summation of market shares for other patented drugs in the same class in each year. This variable, referred to as MSP, allows us to test how market share based on sales data affects a firm's incentive to choose in-house development. Table C.4 provides descriptive statistics for the control variables.

\footnotetext{
${ }^{29}$ Of the drugs that are launched in the Pharmaprojects dataset, we are able to match 57 percent to a listing in the IMS dataset. The 12 classes of drugs common to both datasets are alimentary/metabolic products, blood and clotting products, cardiovascular products, dermatological products, genitourinary products, hormonal products, anti-infective products, musculoskeletal products, neurological products, anti-parasitic products, respiratory products, and sensory products.
} 


\section{Empirical Tests}

In this section we empirically test the theoretical predictions derived in Section 4. We start with the two predictions concerning the role of other patents owned by the originator, and then consider the prediction involving market share. Robustness checks are presented at the end of the empirical analysis. ${ }^{30}$

\subsection{Patent Existence}

To investigate whether owning a patent in the same product class as the drug under development has an effect on the originator's decision whether to develop the product inhouse or outsource, we estimate the following logit specification:

$$
\operatorname{Prob}\left(Y_{i j k t}=1\right)=\Lambda\left(\alpha_{0}+\alpha_{1} E O P_{i j k t}+\alpha_{2} X_{i j t}+\alpha_{3} Z_{j k t}+\alpha_{4} W_{j t}+C_{k}+T_{t}\right)
$$

$\Lambda(\cdot)$ is the standard logistic CDF. The subscripts $i, j, k$, and $t$ index compound, firm, therapeutic class, and year, respectively. $Y_{i j k t}$ is an indicator variable for in-house development. $E O P_{i j k t}$ is a patent existence variable, where in some specifications it is the indicator measure EOP1, in other tests it is the indicator measure EOP2, and in others it is the measure of the expected number of other patented products that will eventually reach the market EOP3. $X_{i j t}$ is a vector of development phase indicator variables. Note that, as discussed earlier, only years prior to phase III are included in our tests, because after the beginning of phase III decisions are highly unlikely to affect the degree of cannibalization. Hence, in the analysis pre-clinical testing is the omitted comparison group, and controls for phase I and phase II trials are included. $Z_{j k t}$ is the originator's development experience in the therapeutic class of the drug under development, while $W_{j t}$ is the originator's therapeutic scope.

Equation (7) also includes therapeutic class fixed effects, $C_{k}$, to control for unobserved class characteristics that affect both patent existence and development integration decisions. Year fixed effects, $T_{t}$, control for across-time differences in firms' preferences concerning the in-house versus outsource decision. From Testable Prediction 1 we expect $\alpha_{1}$ to be positive, i.e., an originator that owns an existing patented product in the same product class as the product under development should be more likely to choose in-house development. ${ }^{31}$

\footnotetext{
${ }^{30} \mathrm{~A}$ more extensive set of empirical tests supporting our predictions can be found in Pan (2016).

${ }^{31}$ We do not include firm fixed effects because, in most cases, a firm has a limited number of products under development in a product class, so including firm fixed effects would eliminate significant variation we use to estimate the coefficients of interest.
} 
Table C.5 reports the regression results. Each patent existence measure (EOP1, EOP2, and EOP3) is estimated under two different specifications. In the first specification therapeutic experience and therapeutic scope are omitted, whereas they are included in the second specification. All regressions employ robust standard errors to account for heteroskedacticity. Also, standard errors are clustered at the compound level to account for potential correlation concerning the in-house versus outsource decision for a particular compound across observations.

The first two columns report results for EOP1. The coefficient on EOP1 is positive and statistically significant at the one-percent level in each regression. The coefficient on the experience variable is also positive and statistically significant at the one-percent level, while the coefficient on the scope variable is negative and statistically significant at the one-percent level. The former result is consistent with therapeutic experience lowering the costs of inhouse development and thus making in-house development more likely, while the latter result is consistent with therapeutic scope lowering costs which makes in-house development more likely (remember that our scope variable is such that a higher value means a less diversified portfolio of projects).

Columns 3 and 4 consider the same set of tests focusing on our patent count variable, and columns 5 and 6 consider the same tests focusing on the variable that measures the expected number of other patented products in the same class that will eventually reach the market. In each set of tests the results are similar to those in columns 1 and 2. The only difference worth noting is that in the column 4 specification the coefficient on the experience variable is positive but statistically insignificant.

Our preferred specification is the one which controls for experience and scope. Using this specification, we now report results concerning how much less licensing occurs prior to phase III when the originator owns patented products in the same product class. The baseline probability that the development of a drug will be observed to be outlicensed by the originator in a year prior to phase III is 19.0 percent. Employing the coefficient on EOP1 in column 2, the probability of licensing prior to phase III is 5.0 percentage points lower when the originator owns at least one other patented compound in the same therapeutic class relative to the probability when the originator owns no such patented compound. We can also do similar calculations employing analogous coefficients in columns 4 and 6 . Using the coefficient on EOP2 in column 4, we estimate that increasing the number of other patented compounds in the same class owned by the originators by one standard deviation decreases the probability of outsourced development by 7.7 percentage points in each year prior to phase III. Using the coefficient on EOP3 in column 6, we estimate that increasing by a standard deviation the expected number of other same-class compounds owned by the 
originators that are expected to reach the market decreases the probability of outsourced development by 2.4 percentage points.

\subsection{Patent Length}

To investigate whether the length of patents owned by originators in the same product class as the drug under development has an effect on the originator's decision whether to develop the product in-house or outsource, we estimate the following logit specification:

$$
\operatorname{Prob}\left(Y_{i j k t}=1\right)=\Lambda\left(B_{0}+B_{1} L O P_{i j k t}+B_{2} X_{i j t}+B_{3} Z_{j k t}+B_{4} W_{j t}+C_{k}+T_{t}\right) .
$$

$L O P_{i j k t}$ is a patent length variable, where in some tests it is the length of the longest patent of the drugs the originator owns in the same class as the drug under development LOP1, in other specifications it is the sum of the patent lengths of the drugs the originator owns in the same class as the drug under development LOP2, and in yet other specifications it is the weighted (by phase-specific success probabilities) sum of the patent lengths of the drugs the originator owns in the same class as the drug under development LOP3. The control variables for development phase $X_{i j t}$, therapeutic experience $Z_{j k t}$, scope $W_{j t}$ and fixed effects for therapeutic category $C_{k}$ and year $T_{t}$ are the same as in Equation (7). From Testable Prediction 2, we expect $B_{1}$ to be positive, i.e., an originator with longer patent life for drugs it owns in the same product class as the drug under development should be more likely to choose in-house development.

Table C.6 reproduces the regressions in Table C.5 where we substitute our patent length variables for the patent existence variables. We start by discussing the results in columns 1 and 2 which employ the patent length variable LOP1. The results here are similar to what we saw for patent existence in Table C.5. First, the coefficient on LOP1 is positive in both regressions, and statistically significant at the one-percent level in each regression. Second, in column 2 the coefficient on the experience variable is positive and statistically significant at the one-percent level, while the coefficient on the scope variable is negative and statistically significant at the one-percent level. The results in columns 3 and 4 for LOP2 and in columns 5 and 6 for LOP3 exhibit similar patterns, except that in column 6 the coefficient on LOP3 is positive but not statistically significant, while the coefficient on the experience variable in column 4 is also positive but not statistically significant. ${ }^{32}$

\footnotetext{
${ }^{32}$ As will become apparent, specifications that include LOP3 are in general less supportive of the theory than those using the patent existence variables or the other patent length variables. There are strong positive correlations between the various patent variables and the experience variable, and we suspect this might be affecting the statistical significance of the coefficients on LOP3 in the specifications that include that variable.
} 
As in the case of patent existence, our preferred specification is the one in which experience and scope variables are included. So we focus on that specification in reporting results concerning how much changes in patent length of patents of other products in the same class owned by originators affects the probability development is conducted in-house. Consider the coefficient in column 2 on LOP1. This coefficient tells us that a one standard deviation increase in the length of the longest patent on any other patent held by the originator in the same product class as the product under development is associated with a 4.0 percentage point decrease in the probability a compound will be in a licensing contract in a year prior to phase III.

We can also conduct similar exercises using results from column 4. Employing the coefficient on LOP2 in column 4 yields that increasing the sum of patent lengths of patented drugs in the same product class owned by the originators by one standard deviation decreases the probability of outsourced development by 7.6 percentage points.

\subsection{Market Share}

This subsection considers tests related to Testable Prediction 3, which is that in-house development should be more common when the originator's market share in the product class is larger. We conduct two sets of tests related to this prediction. The first uses the Pharmaprojects dataset to consider how the number of competing drugs owned by firms other than the originator affects the originator's incentive to choose in-house development. In the second we use IMS sales data to construct an expected market share measure for an originator, and then directly test how expected market share affects the choice of in-house versus outsourced development.

As indicated, we start with tests concerning the number of drugs in the product class owned by other firms. In the following logit specification, we develop a test by interacting the patent existence measure, EOP, with the number of other firms' patented drugs on the market that are in the same therapeutic class as the drug under development. The specific equation that we estimate takes the following form:

$$
\begin{aligned}
\operatorname{Prob}\left(Y_{i j k t}=1\right)=\Lambda\left(\gamma_{0}\right. & +\gamma_{1} E O P_{i j k t}+\gamma_{2} E O P_{i j k t} P D M_{j k t}+\gamma_{3} P D M_{j k t} \\
& \left.+\gamma_{4} T D M_{k t}+\gamma_{5} X_{i j t}+\gamma_{6} Z_{j k t}+\gamma_{7} W_{j t}+C_{k}+T_{t}\right) .
\end{aligned}
$$

TDM is the total number of drugs on the market that are in the same therapeutic class as the drug under development, while PDM is the number of patented drugs on the market in the same therapeutic class as the drug under development but owned by different firms 
than the originator of the compound of interest. Given that we control for TDM, the theory predicts that the effect on the in-house versus outsourcing decision of an existing patent in the same product class owned by an originator should be smaller when there is a higher number of competing patented products on the market owned by other firms, i.e., $\gamma_{2}$ is predicted to be negative. Note that other controls are the same as in Equations (7) and (8) and our focus is our preferred specification which includes controls for experience and scope.

Table C.7 reports results for estimating Equation (9). Column 1 shows results when EOP1 is the patent existence variable. The main result here is that the coefficient on the patent existence variable is positive and statistically significant at the one-percent level, while the coefficient on the interaction term is negative and statistically significant at the one-percent level. Columns 2 and 3 show results for the same test, except that in column 2 EOP2 is the patent existence variable, while in column 3 it is EOP3. The results in these tests are similar but somewhat weaker than in the column 1 test. In particular, in column 2 the coefficient on the interaction term is negative but not statistically significant, while in column 3 the coefficient is negative and statistically significant at the five-percent level. Overall, the results in this table support the prediction.

We now consider a similar set of tests, except our focus is the effect of patent length rather than patent existence on the in-house versus outsourcing decision. In particular, we estimate a logit specification similar to Equation (9), except now the explanatory variable of interest is a measure of patent length rather than patent existence. We again focus on our preferred specification which includes controls for experience and scope.

Results are reported in Table C.8. Column 1 reports results where LOP1 is the patent length measure. In this column the coefficient on LOP1 is positive and statistically significant at the one-percent level, while the coefficient on the interaction term is negative and statistically significant at the one-percent level. Columns 2 and 3 consider the same tests as in column 1, except that in column 2 LOP2 is the patent length variable and in column 3 it is LOP3. The pattern of results in columns 2 and 3 is the same as in column 1. Overall, we again find results consistent with the third testable prediction. That is, longer patent length for products owned by the originator in the same product class as the product under development increases the probability of in-house development, but the effect is weaker the higher the number of patented products in the product class owned by other firms.

We now consider a second approach for measuring how competition from other firms' patented products in the same product class affects the correlations we found in the previous subsections. In particular, rather than focusing on the number of other patented products owned by other firms, we focus on how a firm's expected market share of commercialized patented products in a product class affects the in-house versus outsource decision of the 
later-arriving product. Note that construction of our market share measures requires IMS data which only covers the years between 1992 and 2004. Here we only look at sales data for the 12 therapeutic classes listed in footnote 29. For both reasons the sample sizes for these tests are smaller than for previous tests.

According to Testable Prediction 3, the expected market share when the new drug reaches the market should be positively correlated with the probability of in-house development. That is, it is not the market share at the time of a development decision which should matter, but rather the expectation at the time of a development decision concerning the market share that the firm will have once the new product is introduced. Note that for purposes of this test, we assume that the firm has perfect foresight concerning future market shares since we have no data that directly measures market share expectations at the time of a development decision.

In Table C.9 we examine how market share along with our patent existence measures affects the in-house versus outsource decision. The top panel of the table reports results for the logit specification in Equation (10):

$$
\begin{aligned}
\operatorname{Prob}\left(Y_{i j k t}=1\right)=\Lambda\left(\zeta_{0}\right. & +\zeta_{1} M S P_{i j k t}+\zeta_{2} E O P_{i j k t} \\
& \left.+\zeta_{3} X_{i j t}+\zeta_{4} Z_{j k t}+\zeta_{5} W_{j t}+C_{k}+T_{t}\right) .
\end{aligned}
$$

For each drug under development belonging to an originating firm $j$ and therapeutic class $k, M S P_{i j k t}$ is the market share based on the current year-t sales of patented drugs for the same firm and class. The other regressors are defined the same way as in Equation (7). In the bottom panel, we estimate a similar equation except the current MSP measure is replaced with projected future MSP. The specific equation estimated is given in Equation (11):

$$
\begin{aligned}
\operatorname{Prob}\left(Y_{i j k t}=1\right)=\Lambda\left(\eta_{0}\right. & +\eta_{1} M S P_{i j k t+\tau}+\eta_{2} E O P_{i j k t} \\
& \left.+\eta_{3} X_{i j t}+\eta_{4} Z_{j k t}+\eta_{5} W_{j t}+C_{k}+T_{t}\right) .
\end{aligned}
$$

As indicated, the value for MSP in this specification is the expected value at the current date of what MSP will be at the date the new product is introduced given successful development. Thus, the number of years in the future the expectation concerns depends on the development phase of the observation. We base this value on DiMasi et al. (2003) which 
estimates the average time a drug spends in each development phase. ${ }^{33}$

The top panel shows that the current year MSP is negatively correlated with originators choosing in-house development decisions, but the effect is not statistically significant. In contrast, in the bottom panel we find that expected future MSP is positive and statistically significant at the five-percent level in all specifications. We also find that in both the top and bottom panels the coefficient on the patent existence variable is always positive, and it is statistically significant at the one-percent level in five of the six regressions, where the coefficient on EOP3 in the bottom panel is positive but not statistically significant. These findings are consistent with Testable Prediction 3.

In Table C.10 we rerun the tests in Table C.9 but replace the patent existence variables with the patent length variables. The results are similar. In the top panel the coefficient on current MSP is negative but never statistically significant, while in the bottom panel the coefficient on expected future MSP is always positive and statistically significant at the five-percent level. Also, in both the top panel and bottom panel the coefficients on the patent length variables are always positive, where the coefficient is statistically significant at the one-percent level except for the coefficient on LOP3 in the bottom panel which is not statistically significant.

Note further that the results concerning expected future MSP in Tables C.9 and C.10 suggest that the effect of expected future MSP on in-house development is economically as well as statistically significant. That is, the various coefficients on expected future MSP in the bottom panels of Tables 8 and 9 indicate that a one percentage point increase in the expected future MSP variable is associated with an increase in the probability that a drug will be developed in-house in a given year by between 4.3 and 4.9 percentage points.

\subsection{Robustness Checks}

In this subsection we consider the robustness of our results in two respects. We first consider whether results are robust to how we categorize whether an originator chooses inhouse or outsourced development. We then consider whether results are robust to how we define therapeutic categories. In the analysis above observations are drug-compound years prior to the start of phase III trials, since after the beginning of phase III decisions should not affect the degree of cannibalization. One might argue, however, that the design and nature of a drug is mostly fixed as early as the completion of phase I testing. With this in mind, in Tables C.11 and C.12 we rerun tests reported in Tables C.5 and C.6 with the single change that observations are drug-compound years prior to the beginning of phase II trials.

\footnotetext{
${ }^{33}$ Based on DiMasi et al. (2003), for observations in the pre-clinical phase the expectation is ten years after the observation, for observations in phase I it is also ten years, and for phase II it is eight years.
} 
Table C.11 reports results using our patent existence variables and our preferred specification. The results are similar to the results in Table C.5. The coefficient on the patent existence measure is positive in each regression and also statistically significant at least at the one-percent level in each regression. Table C.12 reports results for our patent length variables. Here the coefficient on the patent length variable is positive and statistically significant at the one-percent level when the patent length variable is LOP1 (column 1) and LOP2T (column 2), while in column 3 the relevant coefficient is positive but not statistically significant.

As indicated, our second set of robustness tests concerns the way we define therapeutic categories. In particular, one might be concerned that our therapeutic categories are too coarse to accurately capture the cannibalization effect that our theory focuses on. That is, if a firm is currently developing one drug that we classify as being in the same therapeutic class as another patented drug the firm owns, but in reality the two drugs are in different markets, then choosing to develop the new drug in-house will not be be due to the firm's incentive to limit cannibalization and protect the value of the patent on the other drug.

To address this concern, we redefine our main explanatory variables, i.e., patent existence and patent length of other drugs owned by originators in the same therapeutic class, by using a set of narrower therapeutic classifications. For example, whereas before anti-arrhythmic drugs and cardiostimulant drugs were classified as being in the same therapeutic class, now they are in separate classes. Results for this modified specification are reported in Table C.13. The coefficients on the patent existence and patent length variables are all positive and statistically significant at the one-percent level, except the coefficient on LOP3 in column 6 which is positive and statistically significant at the five-percent level.

\section{Alternative Explanations}

There are two major alternative explanations for why firms choose to conduct research and development for some products in-house, while outsourcing these activities for other products. One explanation is that the decision depends on a trade-off between providing incentives for research effort and minimizing finance costs. The basic argument, put forth initially in Aghion and Tirole (1994), is that an integrated structure is chosen when providing incentives for research effort is the more important concern. Note that this theoretical approach is quite different from ours. The focus in that analysis is the probability of successful development, while our argument concerns the new product's location in product space and how that might affect the value of existing products through cannibalization.

While we do not doubt that the perspective developed by Aghion and Tirole (1994) is 
important in many real world integration decisions concerning research and development, we feel that this perspective is unlikely to be the correct explanation for the results we find. According to that theory, firms with existing successful patents should be less financially constrained. Therefore, consistent with our findings, in that argument a firm with an existing patent should be more likely to choose in-house development because financing costs will be less of a concern. However, this alternative argument does not explain why current market share of existing patented drugs in the same product class owned by the originators is less successful in predicting in-house development than is future expected market share as shown in Tables C.9 and C.10. So our argument concerning reducing costs of cannibalization does a better job of explaining our empirical findings than does the Aghion and Tirole argument.

Another potential explanation for the in-house versus outsource decision is that firms may choose to develop some products in-house in order to capitalize on past specific investments. Even though in our empirical analysis we control for experience and scope, one might still suspect that the correlation we find between our patent existence and patent length variables and in-house development to some extent reflects past specific investments. This interpretation, however, fails to explain why the positive correlations between in-house development and the various patent existence and patent length variables are weaker when the market is crowded with competing patented drugs ownd by other firms, as found in a number of our tests. Furthermore, the specific investment argument also does not explain our empirical findings concerning expected market share of other patented drugs owned by the originator. In summary, neither of the major alternative explanations can account for our empirical findings as fully as the theory we develop in Sections 3 and 4.

\section{Conclusion}

This paper focuses on the idea that limiting cannibalization of existing patented products owned by originators is important for understanding a firm's decision concerning whether to develop new products in-house or outsource. We begin by constructing and analyzing a theoretical model in which ownership of existing patented products in the same product class as a new product increases the incentive for an originator to develop the new product in-house. The logic is that a licensee has less of an incentive than the originator to avoid cannibalizing the value of current patented products owned by the originators, so in-house development is preferred when avoiding such cannibalization is important. The model generates testable predictions concerning in-house development, patent existence, patent length, and market share for existing patented products.

We employ data from the pharmaceutical industry to investigate the model's predictions. 
Our empirical findings are consistent with the theoretical predictions. First, controlling for firm characteristics and therapeutic class, we find that an originator with existing patented products as the product under development is more likely to develop the new product inhouse. Second, the probability of in-house development also increases with the patent length of patented drugs owned by the originator that are in the same therapeutic class as the drug under development. Third, the relationship between in-house development and our patent existence and patent length variables is weaker when there are more same class patented drugs owned by other firms, holding fixed the total number of same class patented drugs on the market. Fourth, using market share data based on drug sales, we find that the probability a new drug is developed in-house increases with the originating firm's expected future market share of its existing same class patented drugs at the date the new drug is expected to reach the market.

These findings suggest that avoiding cannibalization of existing products is an important factor in determining whether a new product is developed in-house or outsourced. We focus on the incentive for in-house development when the originator owns existing patented products in the same product class, and the originator wants to control the design of the new product. A complementary perspective is that in-house development is also important when the originator owns existing patented products in the same product class that are about to expire, and as a result it is important for the originator to control the timing of the new product introduction. We feel this is an interesting topic for future research. ${ }^{34}$

Another interesting direction for future research is extending the analysis in terms of the nature of the innovation process. In this paper, we focus on a producer developing a new product of given quality that potentially cannibalizes sales of the firm's existing patented products. It would be interesting to investigate what possible additional insights might arise if the nature of the investment such as the quality of the innovation was endogenously determined, and also how rivalry in the innovation process itself might affect our basic conclusions. ${ }^{35}$

\footnotetext{
${ }^{34}$ See Williams (2013) for a related analysis focused on how current intellectual property protection affects the rate of subsequent innovation.

${ }^{35}$ See Gans and Stern (2000) and Igami (2017) for analyses of rivalry in the innovation process, and Budish et al. (2015) and Krieger et al. (2020) for analyses focused on the nature of investments such as the quality of innovations.
} 


\section{References}

Aghion, P., N. Bloom, R. Blundell, R. Griffith, and P. Howitt (2005). Competition and Innovation: An Inverted U-Relationship. Quarterly Journal of Economics 120, 701-728.

Aghion, P. and J. Tirole (1994). The Management of Innovation. Quarterly Journal of Economics 109, 1185-1209.

Akerlof, G. A. (1970). The Market for "Lemons": Quality Uncertainty and the Market Mechanism. Quarterly Journal of Economics 84, 488-500.

Arrow, K. (1962). Economic Welfare and the Allocation of Resources for Invention. In Universities-National Bureau Committee for Economic Research, Committee on Economic Growth of the Social Science Research Council (Ed.), The Rate and Direction of Inventive Activity: Economic and Social Factors, pp. 609-626. NJ: Princeton University Press.

Azoulay, P. (2004). Capturing Knowledge Within and Across Firm Boundaries: Evidence from Clinical Development. American Economic Review 94, 1591-1612.

Balakrishnan, S. and B. Wernerfelt (1986). Technical Change, Competition and Vertical Integration. Strategic Management Journal 7, 347-359.

Barrera, C. and M. Waldman (2019). Vertical Integration, Secrecy, and High Tech Industries. mimeo.

Budish, E., B. N. Roin, and H. Williams (2015). Do Firms Underinvest in Long-Term Research? Evidence from Cancer Clinical Trials. American Economic Review 105, 20442085.

Casas-Arce, P., T. Kittsteiner, and F. A. Martinez-Jerez (2019). Contracting with Opportunistic Partners: Theory and Application to Technology Development and Innovation. Management Science 65, 842-858.

Choi, J. P. (1994). Network Externality, Compatibility Choice, and Planned Obsolescence. The Journal of Industrial Economics 42, 167-182.

Cunningham, C., F. Ederer, and S. Ma (2020). Killer Acquisitions. Journal of Political Economy (forthcoming).

Danzon, P. M., S. Nicholson, and N. S. Pereira (2005). Productivity in PharmaceuticalBiotechnology R\&D: The Role of Experience and Alliances. Journal of Health Economics 24, 317-339.

Demougin, D. M. (1989). A Renegotiation-Proof Mechanism for a Principal-Agent Model with Moral Hazard and Adverse Selection. RAND Journal of Economics 20, 256-266.

Dewatripont, M. (1988). Commitment Through Renegotiation-Proof Contracts with Third Parties. Review of Economic Studies 55, 377-390. 
DiMasi, J. A., R. W. Hansen, and H. G. Grabowski (2003). The Price of Innovation: New Estimates of Drug Development Costs. Journal of Health Economics 22, 151-185.

Galdon-Sanchez, J. E., R. Gil, and A. Bayo-Mariones (2015). Outsourcing of Peripheral Services: Evidence from Spanish Manufacturing Plant-Level Data. European Economic Review 78, 328-344.

Gans, J. S. and S. Stern (2000). Incumbency and R\&D Incentives: Licensing the Gale of Creative Destruction. Journal of Economics \& Management Strategy 9, 485-511.

Gibbons, R. (2005). Four Formal(izable) Theories of the Firm? Journal of Economic Behavior 85 Organization 58, 200-245.

Gil, R. and C. A. Ruzzier (2018). The Impact of Competition on "Make-or-Buy" Decisions: Evidence from the Spanish Local TV Industry. Management Science 64, 1121-1135.

Grossman, S. J. and O. D. Hart (1986). The Costs and Benefits of Ownership: A Theory of Vertical and Lateral Integration. Journal of Political Economy 94, 691-719.

Hart, O. (2017). Incomplete Contracts and Control. American Economic Review 107, 17311752.

Hart, O. and J. Moore (1988). Incomplete Contracts and Renegotiation. Econometrica 56, $755-785$.

Hart, O. and J. Moore (1990). Property Rights and the Nature of the Firm. Journal of Political Economy 98, 1119-1158.

Higgins, M. J. and D. Rodriguez (2006). The Outsourcing of R\&D Through Acquisitions in the Pharmaceutical Industry. Journal of Financial Economics 80, 351-383.

Igami, M. (2017). Estimating the Innovator's Dilemma: Structural Analysis of Creative Destruction in the Hard Disk Drive Industry, 1981-1998. Journal of Political Economy 125, 798-847.

Krieger, J., D. Li, and D. Papanikolaou (2020). Developing New Drugs. mimeo.

Lafontaine, F. and M. Slade (2007). Vertical Integration and Firm Boundaries: The Evidence. Journal of Economic Literature 45, 629-685.

Lakdawalla, D. N. (2018). Economics of the Pharmaceutical Industry. Journal of Economic Literature 56, 397-449.

Lam, M. D. (2004, June 1). Why Alliances Fail. Pharmaceutical Executive.

Lerner, J. and U. Malmendier (2010). Contractibility and the Design of Research Agreements. American Economic Review 100, 214-246.

Lerner, J. and R. P. Merges (1998). The Control of Technology Alliances: An Empirical Analysis of the Biotechnology Industry. The Journal of Industrial Economics 46, 125156. 
Levy, D. T. (1985). The Transactions Cost Approach to Vertical Integration: An Empirical Examination. The Review of Economics and Statistics 67, 438-445.

Moorthy, K. S. and I. P. L. Png (1992). Market Segmentation, Cannibalization, and the Timing of Product Introductions. Management Science 38, 345-359.

Nahm, J. (2004). Durable-Goods Monopoly with Endogenous Innovation. Journal of Economics $\&$ Management Strategy 13, 303-319.

Nicholson, S., P. M. Danzon, and J. McCullough (2005). Biotech-Pharmaceutical Alliances as a Signal of Asset and Firm Quality. Journal of Business 78, 1433-1464.

Novak, S. and S. Stern (2009). Complementarity Among Vertical Integration Decisions: Evidence from Automobile Product Development. Management Science 55, 311-332.

Pan, Y. (2016). Essays in Industrial Organization and Health Economics. Dissertation: Cornell University.

Patel, D. (2017, July 17). The Pros and Cons of Outsourcing. Forbes.

Pisano, G. P. (1990). The R\&D Boundaries of the Firm: An Empirical Analysis. Administrative Science Quarterly 35, 153-176.

Salop, S. C. (1979). Monopolistic Competition with Outside Goods. The Bell Journal of Economics 10, 141-156.

Siebert, R. (2015). Entering New Markets in the Presence of Competition: Price Discrimination versus Cannibalization. Journal of Economics \&6 Management Strategy 24, 369-389.

Tucker, I. B. and R. P. Wilder (1977). Trends in Vertical Integration in the U.S. Manufacturing Sector. The Journal of Industrial Economics 26, 81-94.

Waldman, M. (1993). A New Perspective on Planned Obsolescence. Quarterly Journal of Economics 108, 273-283.

Waldman, M. (1996). Planned Obsolescence and The R\&D Decision. RAND Journal of Economics 27, 583-595.

Williams, H. L. (2013). Intellectual Property Rights and Innovation: Evidence from the Human Genome. Journal of Political Economy 121, 1-27. 